\title{
Uniaxial tensile behavior and mechanism characterization of multi-scale fiber-reinforced cementitious materials
}

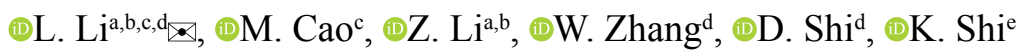 \\ a. Key Laboratory of Agricultural Soil and Water Engineering in Arid and Semiarid Areas of Ministry of Education, \\ Northwest A\&F University, (Yangling, China) \\ b. College of Water Resources and Architectural Engineering, Northwest A\&F University, (Yangling, China) \\ c. Faculty of Infrastructure Engineering, Dalian University of Technology, (Dalian, China) \\ d. State Key Laboratory of Green Building Materials, China Building Materials Academy, (Beijing, China) \\ e. School of Civil Engineering and Architecture, Zhengzhou University of Aeronautics, (Zhengzhou, China) \\ 凶: drlili@nwafu.edu.cn
}

\author{
Received 27 March 2021 \\ Accepted 26 July 2021 \\ Available on line 17 February 2022
}

\begin{abstract}
The uniaxial tensile properties of multi-scale fiber-reinforced cementitious material (MSFRCM) with steel and polyvinyl alcohol (PVA) fibers and calcium carbonate whisker (CW) were studied. The results showed that $\mathrm{CW}$ improved the uniaxial tensile stiffness, strength, peak strain, and toughness of the steel-PVA hybrid fiber-reinforced cementitious material. The $\mathrm{CW}$ not only played a role in the small deformation stage but also improved the load holding capacity and toughness of the hybrid fiber-reinforced cementitious material during the large deformation stage. Computational models to assess the uniaxial tensile strength and toughness of the MSFRCM were established. Microstructure observations showed that the steel and PVA fibers formed a weak interfacial transition zone (ITZ) due to the "wall effect." The CW effectively optimized the structure of the ITZ of the steel and PVA fibers through physical and chemical effects, such as filling, bridging, improving $\mathrm{Ca}(\mathrm{OH})_{2}$ orientation, and chemical effects. The steel fibers, PVA fibers, and CW in the MSFRCM bridged cracks at the macro, mesoscopic, and microscopic levels, respectively. As a result, we observed a fiber chain effect that improved the positive hybrid effect between the multi-scale fibers.
\end{abstract}

KEYWORDS: Hybrid fiber; $\mathrm{CaCO}_{3}$ whisker; Cementitious material; Uniaxial tensile property; Calculations; Micro-mechanism.

Citation/Citar como: Li, L.; Cao, M.; Li, Z.; Zhang, W.; Shi, D.; Shi, K. (2022) Uniaxial tensile behavior and mechanism characterization of multi-scale fiber-reinforced cementitious materials. Mater. Construcc. 72 [345], e271. https://doi.org/10.3989/ mc.2022.05521.

RESUMEN: Comportamiento a tracción uniaxial y caracterización de los mecanismos de materiales base cemento reforzados con fibras multi-escala. Se han estudiado las propiedades de tracción uniaxial de un material cementante reforzado con fibras multiescala (MSFRCM) de acero, de alcohol polivinílico (PVA) y de carbonato cálcico (CW). Los resultados mostraron que las CW mejoraron la rigidez, la resistencia, la deformación máxima y la tenacidad del material cementoso reforzado con fibra híbrida de acero-PVA sometido a tracción uniaxial. Las CW no solo jugaron un papel relevante en la etapa de bajas deformaciones, sino que también mejoraron la capacidad de retención de carga y la tenacidad del material cementante híbrido reforzado con fibras durante la etapa de deformaciones elevadas. Se han establecido modelos computacionales para evaluar la resistencia a la tracción uniaxial y la tenacidad del MSFRCM, y los resultados coincidieron con los resultados de las pruebas así como de los datos de la literatura. Los estudios microestructurales mostraron que el acero y las fibras de PVA formaron una ITZ débil debido al "efecto pared". Las CW optimizaron eficazmente la estructura de la ITZ del acero y las fibras de PVA a través de efectos físicos y químicos como relleno, formación de puentes y mejora de la orientación de la $\mathrm{Ca}(\mathrm{OH})_{2}$. Las fibras de acero, las fibras de PVA y las CW unieron las fisuras de los MSFRCM a nivel macro, meso y microscópico, respectivamente. Como resultado de ello, se observó un efecto de cadena de fibras que mejoró el efecto híbrido positivo entre las fibras multiescala.

PALABRAS CLAVE: Fibra híbrida; Fibra de $\mathrm{CaCO}_{3}$; Material cementosos; Tracción uniaxial; Cálculos; Micro-mecanismos.

Copyright: (C2022 CSIC. This is an open-access article distributed under the terms of the Creative Commons Attribution 4.0 International (CC BY 4.0) License. 


\section{INTRODUCTION}

While cementitious materials are the most extensively used materials in civil engineering and infrastructure, these types of materials have their shortcomings, such as low tensile strength, brittleness, and vulnerability to cracking (1). The failure process of a cementitious material is progressive and multiscale, where the initial internal micro-defects grow, forming meso- and macro-cracks, which negatively affects the mechanical properties and durability of a cementitious material (2-5). To control different stages of cracks in cement-based materials, hybrid fibers of various sizes and physical properties are used $(1,6-10)$. In addition, cheap and expensive fibers are generally an effective way to improve the cost of fiber-reinforced cementitious materials.

However, typical fiber sizes are too large to control pre-existing micron defects or cracks in cementitious materials $(2,11-13)$. Therefore, micro- and nano-sized fibrous materials are used to reinforce cementitious materials. Among these fibers, carbon nanofibers and nanotubes are the two most widely studied nanofibers $(14,15)$. However, both of these fibers are too expensive to be widely used in civil engineering. Hence, micron-sized calcium carbonate whisker $(\mathrm{CW})$ was introduced to reinforce cementitious materials, as this material is much cheaper than nanofibers (about \$230/ton) $(16,17)$. Moreover, using cheaper CW materials instead of other fibers can reduce the cost of fiber-reinforced cementitious materials (17). The CW material can also be used for the multi-scale reinforcement of various cement-based materials. For example, CWPVA multi-scale fiber-reinforced ultra-ductile concrete has better strength, deformation ability, and robustness compared with mono PVA fiber-reinforced concrete (12). In normal concrete, the combination of steel-basalt hybrid fibers and $\mathrm{CW}$ increases the compressive, splitting tensile, and bending properties of the material (18). In ultra-low-weight foamed concrete, the synergistic effects of polypropylene and CWs were also studied (2). Therefore, because of their excellent properties, multi-scale fiber-reinforced cementitious materials (MSFRCMs) containing $\mathrm{CW}$ and macro fibers have widespread potential in civil engineering applications.

Uniaxial tensile strength is one of the most fundamental mechanical properties of fiber-reinforced concrete. It comprises the basis for studying the failure mechanisms and strength theory of fiber-reinforced concrete and also directly affects the cracking, deformation, and durability of fiber-reinforced concrete structural members $(1,19,20)$. Currently, scholars have studied the uniaxial tensile stressstrain relationship of fiber-reinforced concrete $(1$, $21,22)$. However, to the best of the authors' knowledge, there is little information about the uniaxial tensile performance of cement-based materials con- taining $\mathrm{CW}$ and macro-fibers. Therefore, to bridge this knowledge gap, the effects of CW, PVA, and steel multi-scale fibers on the uniaxial tensile behavior of cement-based materials were studied. The complete stress-strain curves of MSFRCMs under uniaxial tension were obtained, and the effects of the multi-scale fibers were evaluated. Based on the synthetic fiber properties, predictive equations for the strength and toughness of the MSFRCMs under uniaxial tensile load were established. In addition, micro-observations and component analysis were employed to understand the microstructural evolution of multi-scale fibers under tensile load.

\section{MATERIALS AND TESTING}

\subsection{Material and specimen preparation}

In this study, the main binder materials consisted of $70 \mathrm{wt} . \%$ of ordinary Portland cement and $30 \mathrm{wt} . \%$ of fly ash. The chemical compositions of the $\mathrm{CaCO}_{3}$ whisker, cement, and fly ash are listed in Table 1. The fine aggregate consisted of quartz sand, and a polycarboxylic acid superplasticizer (water reducing ratio of $32 \%$ ) was employed to control the workability of the fresh mixture. The size and mechanical properties of the steel and PVA fibers, as well as the $\mathrm{CaCO}_{3}$ whisker material, are illustrated in Table 2 . The water-binder and sand-binder ratios were 0.3 and 0.5 , respectively. The full mixing specifications, including the binder and fine aggregate content and superplasticizer dosage, are shown in Table 3 . In addition, the flow spread values obtained by the minislump test (23) are also shown in Table 3. The flow spread was generally higher than $18 \mathrm{~mm}$ and met the requirements of self-compacting fiber-reinforced mortar (24).

The various MSFRCM fiber combinations are illustrated in Table 3, and Figure 1 depicts the mixing process of the MSFRCM. To produce the samples, fresh MSFRCM mortars were cast into dog-bone steel molds and vibrated for 60s. Afterward, while still in the mold, the samples were covered with plastic film, and then removed from the mold after $24 \mathrm{~h}$. Finally, the samples were stored in a $20 \pm 3^{\circ} \mathrm{C}$ water tank for 28 days of curing.

\subsection{Experimental methods}

A custom-designed dog bone plate was used for direct tensile testing of the MSFRCM specimens. The specimen shape, size, and loading conditions are illustrated in Figure 2. Using an MTS hydraulic servo testing machine, direct tensile testing was carried out at a loading rate of $0.1 \mathrm{~mm} / \mathrm{min}$. A displacement sensor was used to assess the deformation of 
TABLE 1. Chemical compositions of the cement and CW (wt.\%).

\begin{tabular}{lllllllllll}
\hline Constituent & $\mathrm{CaO}$ & $\mathrm{SiO}_{2}$ & $\mathrm{Al}_{2} \mathrm{O}_{3}$ & $\mathrm{Fe}_{2} \mathrm{O}_{3}$ & $\mathrm{MgO}$ & $\mathrm{SO}_{3}$ & $\mathrm{~K}_{2} \mathrm{O}$ & $\mathrm{TiO}_{2}$ & $\mathrm{Cl}$ & $\mathrm{SrO}$ \\
\hline $\mathrm{CW}$ & 92.31 & 0.44 & 0.10 & 0.19 & 5.96 & 0.60 & - & - & 0.32 & 0.07 \\
\hline Cement & 58.61 & 22.58 & 6.01 & 4.17 & 1.91 & 4.57 & 1.18 & 0.43 & - & 0.24 \\
\hline Fly ash & 5.13 & 55.06 & 26.50 & 6.07 & 0.80 & 1.06 & 2.54 & 1.51 & - & 0.15 \\
\hline
\end{tabular}

TABLE 2. Size and mechanical properties of the fibers and CW material.

\begin{tabular}{cccccc}
\hline Fiber type & Length/mm & Aspect ratio & Tensile strength/MPa & E-modulus $/ \mathrm{GPa}$ & Density $/\left(\mathrm{kg} / \mathrm{m}^{3}\right)$ \\
\hline Steel fiber & 13 & 65 & $\geq 2,000$ & 210 & 7800 \\
\hline PVA fiber & 6 & 151.1 & 1529.5 & 36.7 & 1300 \\
\hline $\begin{array}{c}\mathrm{CaCO}_{3} \text { whis- } \\
\text { ker }\end{array}$ & $0.02-0.03$ & $10-60$ & $3000-6000$ & $410-710$ & 2860 \\
\hline
\end{tabular}

TABLE 3. MSFRCM with various fiber proportions.

\begin{tabular}{cccccccccc}
\hline \multirow{2}{*}{ Group } & \multicolumn{4}{c}{ Dosage $\left(\mathrm{kg} \cdot \mathrm{m}^{-3}\right)$} & & $\begin{array}{c}\text { Flow } \\
\text { spread } \\
(\mathrm{mm})\end{array}$ & $\begin{array}{c}\text { Compressive } \\
\text { strength } \\
(\mathrm{MPa})\end{array}$ & $\begin{array}{c}\text { Bending } \\
\text { strength } \\
(\mathrm{MPa})\end{array}$ \\
\cline { 2 - 9 } & Steel & PVA & CW & Binder & Sand & $\begin{array}{c}\text { Super- } \\
\text { plasticizer }\end{array}$ & & & \\
\hline Plain & 0 & 0 & 0 & 1220 & 610 & 5.12 & 24.2 & 48.3 & 8.7 \\
\hline S2 & 156 & 0 & 0 & 1195 & 597.5 & 5.44 & 23.1 & 63.2 & 15.6 \\
\hline S1.5P0.5 & 117 & 6.45 & 0 & 1195 & 597.5 & 7.11 & 19.6 & 55.4 & 18.8 \\
\hline S1.5P0.4W1 & 117 & 5.16 & 28.6 & 1184 & 592.0 & 8.29 & 20.3 & 57.1 & 20.1 \\
\hline S1.25P0.75 & 97.5 & 9.68 & 0 & 1195 & 597.5 & 9.62 & 17.1 & 53.2 & 18.3 \\
\hline S1.25P0.55W2 & 97.5 & 7.10 & 57.2 & 1173 & 586.5 & 10.88 & 18.3 & 53.6 & 19.3 \\
\hline
\end{tabular}

Note: steel: steel fiber; PVA: polyvinyl alcohol fiber; $\mathrm{CW}: \mathrm{CaCO}_{3}$ whisker.
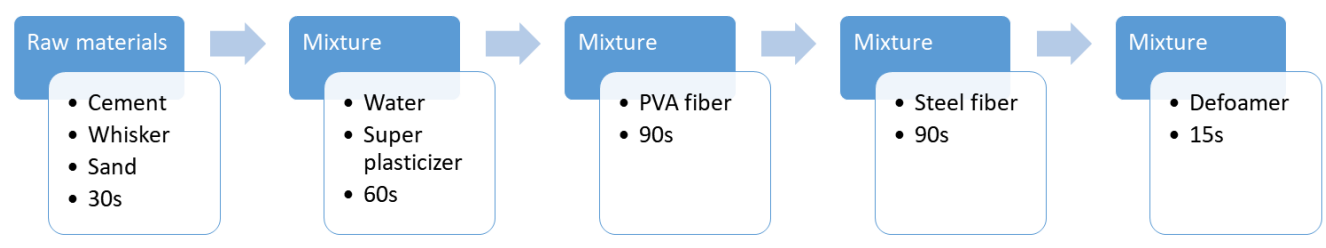

FIGURE 1. Mixing proportions for MSFRCM.

the $50 \mathrm{~mm}$ long section located in the middle of the dog bone specimens. Testing comprised four samples for every mixture, and all of the data averaged the results of the four specimens.

For each mixture, three prisms $40 \mathrm{~mm} \times 40 \mathrm{~mm} \times$ $160 \mathrm{~mm}$ in size were used to conduct the three-point bending and compression tests according to the ISO 679-2009 and GB/T 50081-2002 standards. The compression strength was tested by the two prism halves that were left after bending tests. The compression and bending strengths are shown in Table 3 .
Scanning electron microscopy (SEM) was used to observe the hydration products and $\mathrm{CW}$ in the interfacial transition zone (ITZ), located between the fiber and matrix. Additionally, backscattered electron imagery and energy spectrums were used to analyze the elemental changes in the ITZ. From the microstructure studies, the micro-mechanisms of $\mathrm{CW}$ on the direct tensile behavior of the MSFRCM were deduced. 


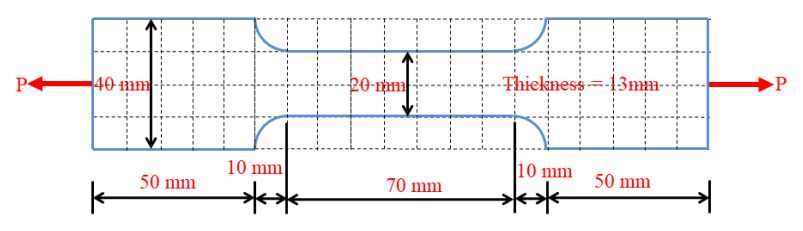

FigURE 2. Direct tensile test specimen.

\section{UNIAXIAL TENSILE PROPERTIES}

\subsection{Uniaxial tensile stress-strain curve}

Figure 3(a) shows the full uniaxial tensile stressstrain curve of the MSFRCM. To clearly analyze the crack inhibition effect of the steel and PVA fibers and $\mathrm{CW}$ during early stages of fracture, the curve for $0-0.2 \%$ strain range was enlarged, as shown in Figure 3(b), which showed that the plain group presented obvious brittle failure. According to Figure 3(b), although the curves somewhat fluctuated, the introduction of steel and PVA fibers and CW material significantly changed the direct tensile stiffness of the MSFRCM, as evidenced by the changes in the slopes of each curve in the $0-0.02 \%$ strain range. The stiffness of S2 significantly increased compared with the plain group, due to the effects of the short steel fibers with high elastic modulus. However, when the steel fiber material was replaced with the same amount of PVA fiber, the stiffness of S1.5P0.5 and S1.25P0.75 was significantly lower compared with the $\mathrm{S} 2$ group. Moreover, the stiffness of S1.25P0.75 with higher PVA fiber content was lower than S1.5P0.5, due to the effects of the flexible PVA fiber. However, after replacing PVA with 1 vol\% of CW, S1.5P0.4W 1 was stiffer than S1.5P0.5. In addition, S1.25P0.55W2 was stiffer than $\mathrm{S} 1.25 \mathrm{P} 0.75$, due to the optimization of the micropores and the control of micro-cracks by $\mathrm{CW}$ with a high elastic modulus.

As shown in Figure 3(b), when the strain was

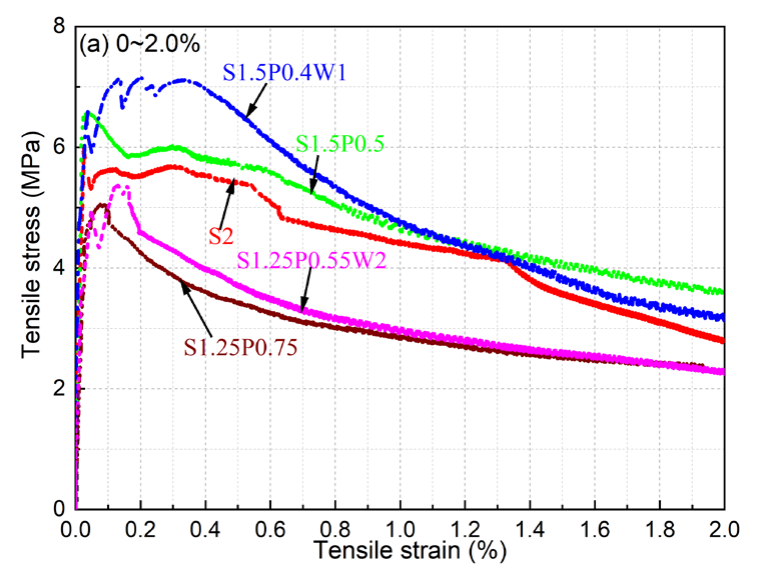

$0.02 \%-0.05 \%$, the curves of each group reached their initial peak strength, and the rapid stress growth stage was over; thus, the stress entered a stable or slow decline stage. Therefore, the overall stress magnitude relationship was $\mathrm{S} 1.5 \mathrm{P} 0.5 \approx \mathrm{S} 1.5 \mathrm{P} 0.4 \mathrm{~W} 1>$ $\mathrm{S} 2>\mathrm{S} 1.25 \mathrm{P} 0.75 \approx \mathrm{S} 1.25 \mathrm{P} 0.55 \mathrm{~W} 2$. After reaching the first peak strength, the variations for each group were different. The S2 stress initially decreased significantly, and then the stress remained stable at about $0.5 \%$ strain. The $\mathrm{S} 1.5 \mathrm{P} 0.5$ group was similar compared with $\mathrm{S} 2$, and the stress was basically stable within $0.5 \%$ strain. The stress of S1.5P0.5 was higher than that of S2 and decreased more slowly. The curve of S1.5P0.5 was smoother, more convex, and fuller than S2, indicating that more energy was consumed when the load was applied. This proved that the hybrid effect of the PVA and steel fibers not only improved strength but also optimized ductility and toughness (25). While the stress of $\mathrm{S} 1.5 \mathrm{P} 0.4 \mathrm{~W} 1$ decreased at first, it subsequently increased significantly. When the strain value was about $0.07 \%$, the stress of $\mathrm{S} 1.5 \mathrm{P} 0.4 \mathrm{~W} 1$ exceeded that of S1.5P0.5, showing obvious strain-hardening characteristics. The tensile stress variations of the $\mathrm{S} 1.25 \mathrm{P} 0.55 \mathrm{~W} 2$ and $\mathrm{S} 1.25 \mathrm{P} 0.75$ groups were similar to the $\mathrm{S} 1.5 \mathrm{P} 0.4 \mathrm{~W} 1$ and $\mathrm{S} 1.5 \mathrm{P} 0.5$ groups. However, the tensile stress values of the S1.25P0.55W2 and $\mathrm{S} 1.25 \mathrm{P} 0.75$ groups were lower than the S2 group, due to lower steel fiber content.

As shown in Figure 3(a), when the strain rate was higher than $0.2 \%$, the $\mathrm{S} 1.5 \mathrm{P} 0.4 \mathrm{~W} 1$ curve was mostly flat and smooth. When the steel fiber content of S1.5P0.4W1 was less than the S2 group, the PVA fiber content of S1.5P0.4W1 was less than the $\mathrm{S} 1.5 \mathrm{P} 0.5$ group. During the large deformation stage, S1.5P0.4W1 exhibited good deformation capacity and energy consumption. This indicated that $\mathrm{CW}$ not only limited crack formation during the initial stage and increased the stiffness of the cementitious material but also optimized the fiber/matrix interface and improved the reinforcing abilities of the steel

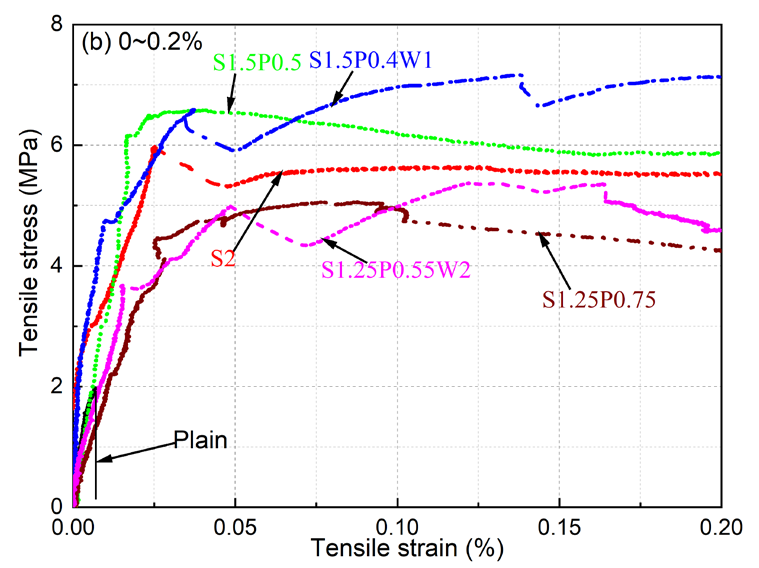

FIGURE 3. Direct tensile stress-strain curves of MSFRCM for various strain scopes. 
and PVA fibers. However, when the strain was about $1.2 \%$, the stress of $\mathrm{S} 1.5 \mathrm{P} 0.4 \mathrm{~W} 1$ decreased slightly compared with the $\mathrm{S} 1.5 \mathrm{P} 0.5$ group. This was due to the lower quantity of PVA fibers, leading to a slight decrease in its load-holding capacity at a larger scale.

\subsection{Uniaxial tensile strength and deformation}

Compared with the control group, the peak strength $\left(f_{d \mathrm{p}}\right)$ of the fiber-doped group significantly increased by more than $200 \%$, as shown in the second column of Table 4. Compared with S2, the S1.5P0.5 and $\mathrm{S} 1.5 \mathrm{P} 0.4 \mathrm{~W} 1$ groups significantly improved by $10.0 \%$ and $19.9 \%$, respectively. The peak strength of the S1.5P0.4W1 group was the highest, showing the optimization effect of $\mathrm{CW}$ on the hybrid fiber system and proving the feasibility of partly replacing steel and PVA fibers with CW. The peak strength value of S1.25P0.75 and S1.25P0.55W2 was lower than S2 due to the decrease in steel fiber content, and was different from the bending strength, indicating that the tensile strength was more sensitive to the decrease in steel fiber content. In addition, when the data in Tables 3 and 4 were compared, the uniaxial tensile strength was significantly lower than the bending strength. This occurred mainly because under direct tensile load, the entire cross-section of the specimen was under the action of tensile stress. The cross-section area of the direct tensile specimen was smaller than the bending specimen; thus, there was less total fiber content in the direct tensile specimen section subjected to testing. Consequently, the direct tensile specimen was more sensitive to a decrease in the number of steel fibers. However, under bending load, only part of the section was in tension; thus, the peak strength was high and was insensitive to the changes in the number of steel fibers (26).

The increase in the peak strain $\left(\varepsilon_{d \mathrm{p}}\right)$ of the fiber-doped group was more significant than the peak strength, and the increase was more than $270 \%$, as shown in the third column of Table 4. Compared with S2, the peak strain of all the hybrid fiber groups improved to varying degrees, increasing by $64 \%-$ $460 \%$. The peak strains of S1.5P0.5 and S1.25P0.75 increased by $64 \%$ and $252 \%$, respectively. The increased peak strain rates of $\mathrm{S} 1.5 \mathrm{P} 0.4 \mathrm{~W} 1$ and S1.25P $0.55 \mathrm{~W} 2$ were $460 \%$ and $380 \%$, respectively, indicating that $\mathrm{CW}$ and the PVA fibers improved the deformation capacity of the cementitious materials.

Similar to the bending performance, residual strengths $f_{d 0.1}$ and $f_{d 1.0}$ for specified strains of $0.1 \%$ and $1 \%$ were introduced, and the corresponding residual strengths of each group were compared with S2, as shown in Table 4. The plain group lost its bearing capacity after reaching peak strength, and the residual strength was zero. The bearing capacity of the fiber specimens decreased slowly after reaching peak load, and $f_{d 0.1}$ and $f_{d 1.0}$ showed the same variation trends,
TABLE 4. Direct tensile behavior indexes of MSFRCM (MPa).

\begin{tabular}{ccccc}
\hline Group & $f_{d \mathrm{p}}$ & $\varepsilon_{d \mathrm{p}}(\%)$ & $f_{d 0.1}$ & $f_{d 1.0}$ \\
\hline $\begin{array}{c}\text { Plain } \\
1.98 \pm 0.02\end{array}$ & $0.067 \pm 0.003$ & - & - \\
\hline $\mathrm{S} 2$ & $5.98 \pm 0.38$ & $0.25 \pm 0.013$ & $5.63 \pm 0.41$ & $4.42 \pm 0.31$ \\
\hline $\mathrm{S} 1.5 \mathrm{P} 0.5$ & $6.58 \pm 0.20$ & $0.41 \pm 0.022$ & $6.18 \pm 0.31$ & $4.66 \pm 0.19$ \\
\hline $\mathrm{S} 1.5 \mathrm{P} 0.4 \mathrm{~W} 1$ & $7.17 \pm 0.42$ & $1.4 \pm 0.084$ & $6.96 \pm 0.38$ & $4.77 \pm 0.17$ \\
\hline $\mathrm{S} 1.25 \mathrm{P} 0.75$ & $5.06 \pm 0.16$ & $0.88 \pm 0.043$ & $4.94 \pm 0.10$ & $2.85 \pm 0.09$ \\
\hline $\mathrm{S} 1.25 \mathrm{P} 0.55 \mathrm{~W} 2$ & $5.37 \pm 0.19$ & $1.2 \pm 0.096$ & $4.98 \pm 0.13$ & $2.91 \pm 0.04$ \\
\hline
\end{tabular}

Note: $f_{d p}$ : peak strength; $\varepsilon_{d p}$ : strain corresponding to peak strength; $f_{d 0.1}$ and $f_{d 1.0}:$ residual strength at $0.1 \%$ and $1.0 \%$ strain, respectively.

namely S1.5P0.4W1 $>\mathrm{S} 1.5 \mathrm{P} 0.5>\mathrm{S} 2>\mathrm{S} 1.25 \mathrm{P} 0.55 \mathrm{~W} 2>$ $\mathrm{S} 1.25 \mathrm{P} 0.75$. In terms of residual strength, the positive hybrid effect of the hybrid fiber system was evident, especially for $\mathrm{S} 1.5 \mathrm{P} 0.4 \mathrm{~W} 1 . f_{d 1.0}$ of $\mathrm{S} 1.5 \mathrm{P} 0.4 \mathrm{~W} 1$ reached $4.77 \mathrm{MPa}$, and the load-holding capacity significantly improved. However, the load holding capacity of S1.25 $0.55 \mathrm{~W} 2$ and $\mathrm{S} 1.25 \mathrm{P} 0.75$ obviously decreased, and $f_{d 1.0}$ decreased to about $50 \%$ of the peak strength.

\subsection{Uniaxial tensile to compressive strength and uniaxial tensile to flexural strength}

The tensile to compressive strength ratio (T/C ratio) is often employed to assess the toughness of cementitious materials $(8,17)$, and a higher $\mathrm{T} / \mathrm{C}$ ratio generally indicates better toughness. The T/C ratios of all the fiber-reinforced cementitious materials were about $100 \%-200 \%$ higher than that of the plain matrix, and the data are shown in Figure 4(a). Thus, the T/C ratios of all the hybrid fiber-reinforced cementitious materials were higher than S, especially for $\mathrm{S} 1.5 \mathrm{P} 0.5$ and $\mathrm{S} 1.5 \mathrm{P} 0.4 \mathrm{~W} 1$. In addition, the introduction of $\mathrm{CW}$ further improved the $\mathrm{T} / \mathrm{C}$ ratio. The details of uniaxial tensile toughness will be discussed in the following sections.

The tensile to bending strength ratios ( $\mathrm{T} / \mathrm{B}$ ratio) are shown in Figure 4(b). The T/B ratios for all the fiber-reinforced cementitious material were about $20 \%-70 \%$ higher than the plain matrix. As a result, it appears that the steel fiber content controlled the $\mathrm{T} / \mathrm{B}$ ratio of the fiber-reinforced cementitious material. Thus, the higher the steel fiber content, the higher the T/B ratio. Additionally, replacing PVA fibers with $\mathrm{CW}$ slightly increased the $\mathrm{T} / \mathrm{B}$ ratio. Of 


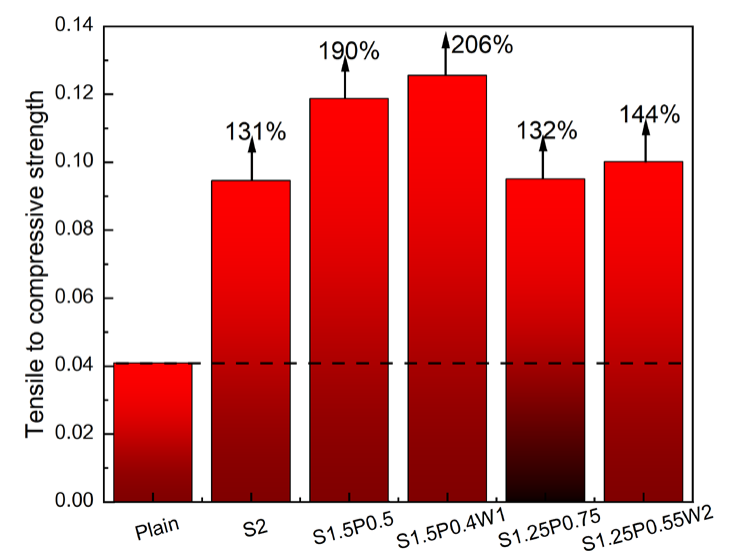

FigURE 4. Ratio of uniaxial tensile strength (a) to compressive strength and (b) bending strength.

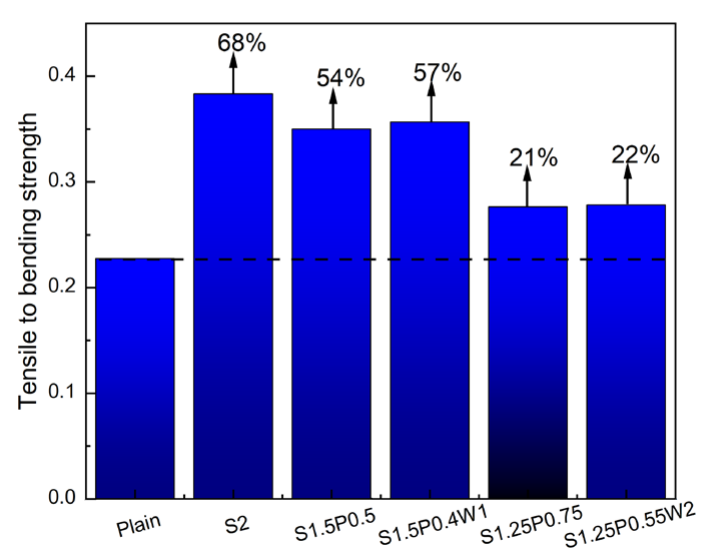

\section{CALCUlation OF UNIAXIAL TENSILE BEHAVIOR}

Based on computational formulas found in the literature (9), a computational formula was employed to calculate the uniaxial tensile behavior (TB) of the hybrid fiber-reinforced cementitious material according to Equation [1]:

$$
\mathrm{TB}=\mathrm{TB}_{0}\left(\alpha \mathrm{RI}_{V}^{2}+\beta \mathrm{RI}_{V}+1\right)
$$

where $\mathrm{TB}$ and $\mathrm{TB}_{0}$ denote the uniaxial tensile properties (strength, strain energy) of the fiber-reinforced and plain cementitious materials, respec-

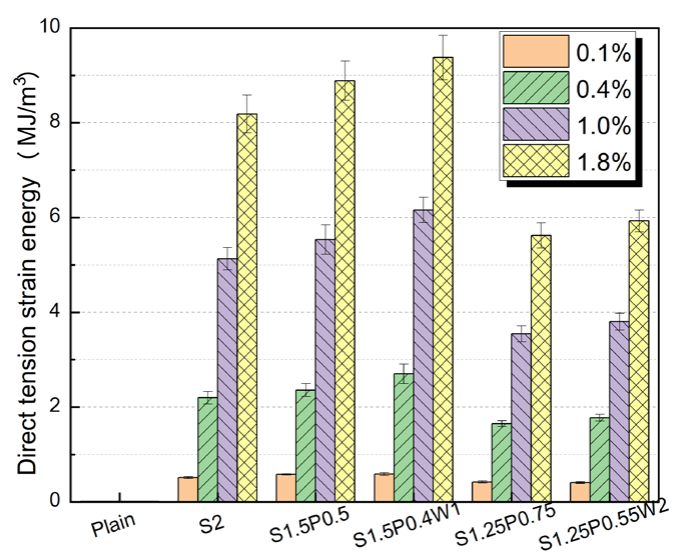

FIGURE 5 Direct tension strain energy of MSFRCM

tively, and $\alpha, \beta$ are the regression coefficients. Additionally, $\mathrm{RI}_{V}$ is the reinforcing index of the hybrid fibers, which is calculated from the volume fraction, tensile strength, and fiber shape, as defined by Equation [2]:

$$
\mathrm{RI}_{V}=\sum_{i}^{n} k_{i} V_{i} \frac{l_{i}}{d_{i}}\left(\frac{f_{t i}}{f_{t s}}\right)^{n}
$$

where $f_{t i}$ and $f_{t s}$ are the tensile strength of the $i$ th 
fiber and steel fiber, respectively. The values of the bond parameter, $k$, for straight steel, PVA fiber, and $\mathrm{CW}$ were all fixed as 0.1 , and the value of the fiber type factor, $\eta$, for both the PVA fiber and $\mathrm{CW}$, was fixed as 0.5 .

Combined with the analysis of the test data, Equation [1] was used to establish a relationship between the uniaxial tensile performance indexes and the fiber index $\mathrm{RI}_{V}$ of the MSFRCM, and the overall correlation was good, as shown in Equations [3-8]: peak strength:

$$
f_{d p}=1.98\left(1-66.02 \mathrm{RI}_{V}{ }^{2}+23.92 \mathrm{RI}_{V}\right), R^{2}=0.85,
$$
peak strain:

$$
\varepsilon_{d p}=0.0067\left(1+256.96 \mathrm{RI}_{V}{ }^{2}+12.28 \mathrm{RI}_{V}\right), R^{2}=0.74,
$$

strain energy between $0-0.1 \%$ :

$\mathrm{TI}=0.0085\left(1-2075.29 \mathrm{RI}_{V}{ }^{2}+717.65 \mathrm{RI}_{V}\right), R^{2}=0.91,[5]$ strain energy between $0-0.4 \%$ :

$\mathrm{TI}=0.0085\left(1-890.71 \mathrm{RI}_{V}{ }^{2}+2969.29 \mathrm{RI}_{V}\right), R^{2}=0.86, \quad$ [6] strain energy between $0-1.0 \%$ :

$\mathrm{TI}=0.0085\left(1-19564.71 \mathrm{RI}_{V}{ }^{2}+9356.47 \mathrm{RI}_{V}\right), R^{2}=0.99$,

strain energy between $0-1.8 \%$ :

$\mathrm{TI}=0.0085\left(1-20187.06 \mathrm{RI}_{V}{ }^{2}+10535.29 \mathrm{RI}_{V}\right), R^{2}=0.98 . \quad$ [8]

The fitting results of the new model in this study

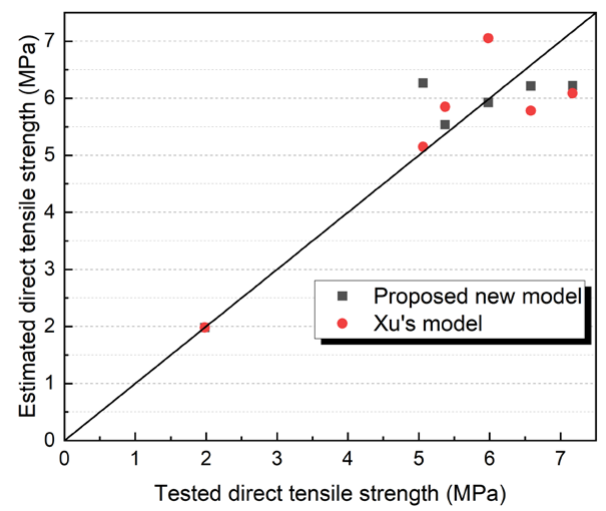

(a) Direct tensile strength

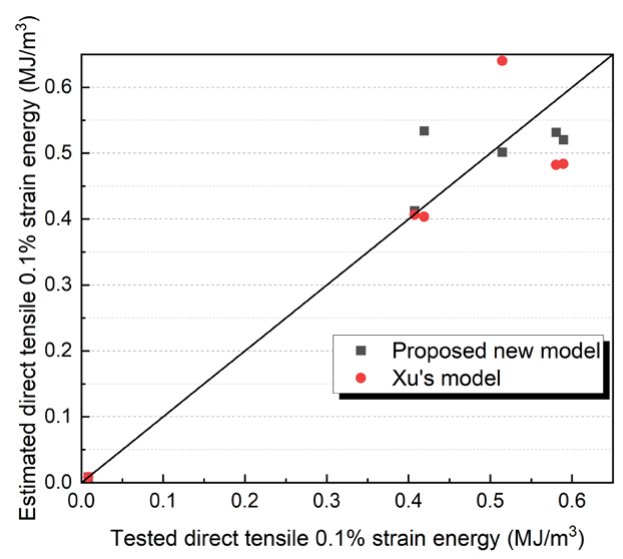

(c) Direct tensile $0.1 \%$ strain energy were superior to Xu's model (1), as shown in Figure 6.

To investigate the applicability of the new model proposed in this study, the experimental data of the hybrid fiber cementitious materials in the literature were analyzed using this model. Xu et al. (1) studied the uniaxial tensile properties of steel-polypropylene hybrid fiber-reinforced concrete with different aspect ratios. Thus, Equation [1] was used to fit the uniaxial tensile peak strength, peak strain, and postpeak tensile strain energy data from Xu's research (1). The steel fiber consisted of corrugated steel fiber, and the anchoring coefficient $k_{i}$ was set to 1 , while the anchoring coefficient of the polypropylene fiber remained as 0.1 . The data fitting results were calculated according to Equations [9-11]: peak strength:

$$
f_{d p}=2.96\left(1-0.12 \mathrm{RI}_{V}{ }^{2}+0.65 \mathrm{RI}_{V}\right), R^{2}=0.79,
$$

peak strain:

$$
\varepsilon_{d p}=123.6 \times 10^{-6}\left(1+0.47 \mathrm{RI}_{V}{ }^{2}+1.42 \mathrm{RI}_{V}\right), R^{2}=0.60,
$$

post-peak tensile strain energy:

$$
\mathrm{TI}=192.7\left(1-18.28 \mathrm{RI}_{V}{ }^{2} \quad 55.32 \mathrm{RI}_{V}\right), R^{2}=0.76 \text {. }
$$

Due to the variety of the steel fibers and the complexity of the system, the correlation was somewhat affected. Nevertheless, the overall correlation was acceptable, indicating that the mathematical rela-

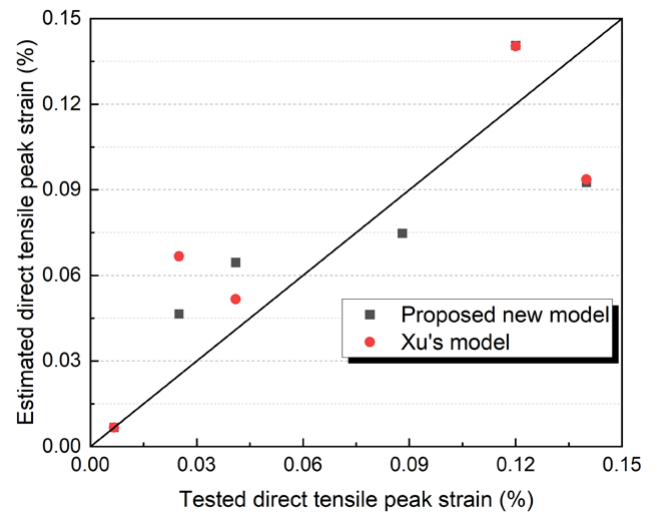

(b) Direct tensile peak strain

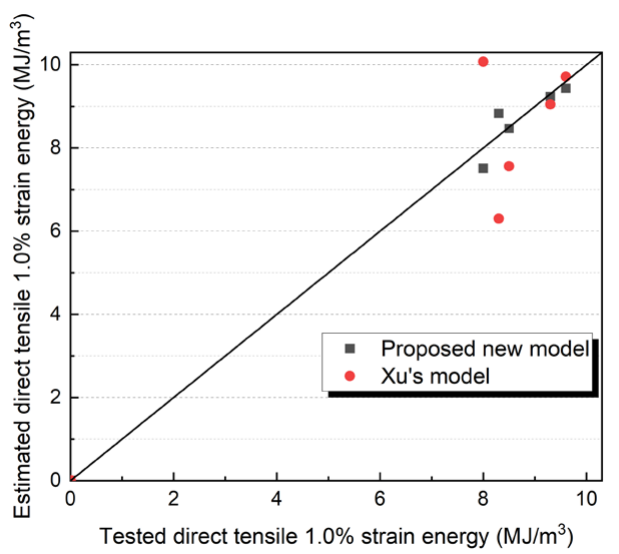

(d) Direct tensile $0.1 \%$ strain energy

FIGURE 6. Predicted values vs. experimental values of the direct tensile properties of MSFRCM. 
tionship was applicable to the uniaxial tensile performance of the steel-polypropylene fiber-reinforced concrete with corrugated steel fibers.

\section{MICRO-MECHANISM DISCUSSION}

\subsection{Microstructure and mechanism analysis of the fiber/matrix interface in the MSFRCM}

The fiber effect in cementitious materials depends on the physical properties of the fiber itself and its quantity. This is discussed in Section 4, and a quantitative calculation model was established. However, this effect also depends on the interactions between the fibers and the cementitious material matrix. That is, the interface between the fiber and matrix will significantly affect the reinforcing effect of the fiber, which will be discussed in this section.

Figure 7 shows the microstructure of the steel and PVA fibers and matrix, as obtained via SEM. As shown in Figure 7(a), the area neighboring the steel fiber consisted of a dense calcium silicate hydrate $(\mathrm{C}-\mathrm{S}-\mathrm{H})$ gel. The region slightly further away from the steel fiber was a loose and porous region
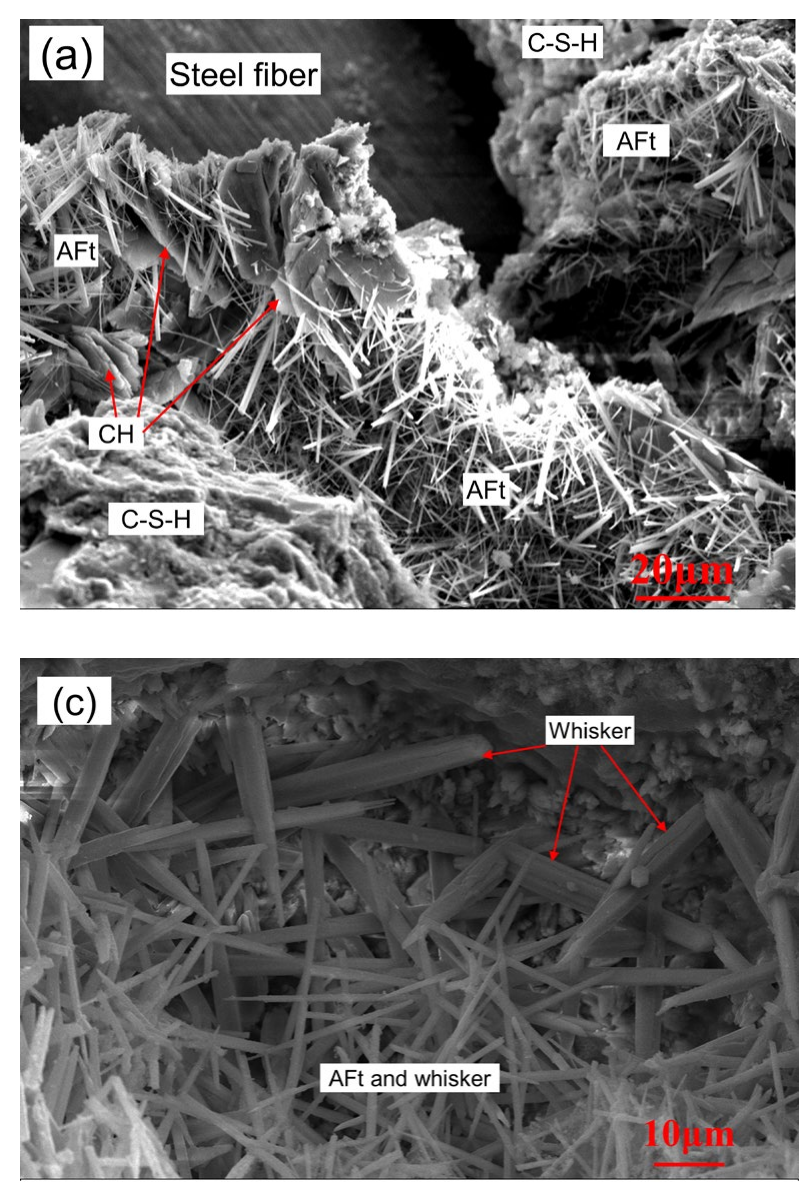

composed of needle-like ettringite (AFt) and hexagonal plate-like $\mathrm{Ca}(\mathrm{OH})_{2}$ crystals, designating the ITZ area. The cement matrix far away from the steel fibers was still dominated by C-S-H gel. As shown in Figure 7(b), the PVA fiber surface was also enriched with dense $\mathrm{C}-\mathrm{S}-\mathrm{H}$ gel and discernable porous loose bands formed outwardly (designated by the dotted line in Figure 7(b)). The arrow in Figure 7(b) shows the loose and porous area at the ITZ, bridged by larger-sized CW. An enlarged rectangular frame is shown in Figure 7(b) and depicted in Figure 7(c), which highlights the large $\mathrm{CW}$ material, while the smaller-sized material may be CW or AFt. CW clusters will play a filling role similar to micro-aggregates in the ITZ near the PVA fiber, improving the pore structure in the ITZ of the PVA fiber (27).

As shown in Figure 7(d), the ITZ on the steel and PVA fiber surfaces could be divided into three regions (28). Region 1 was adjacent to the fiber, where the amount of C-S-H gel was relatively large. In region 2, which was slightly distanced from the fiber, there were a few C-S-H gels mainly composed of $\mathrm{Ca}(\mathrm{OH})_{2}$ and an AFt network structure, forming numerous pores. This was the weakest part of the ITZ. In region 3, far from the fibers, the $\mathrm{C}-\mathrm{S}-\mathrm{H}$ gel content gradually increased, while the content of $\mathrm{Ca}(\mathrm{OH})_{2}$
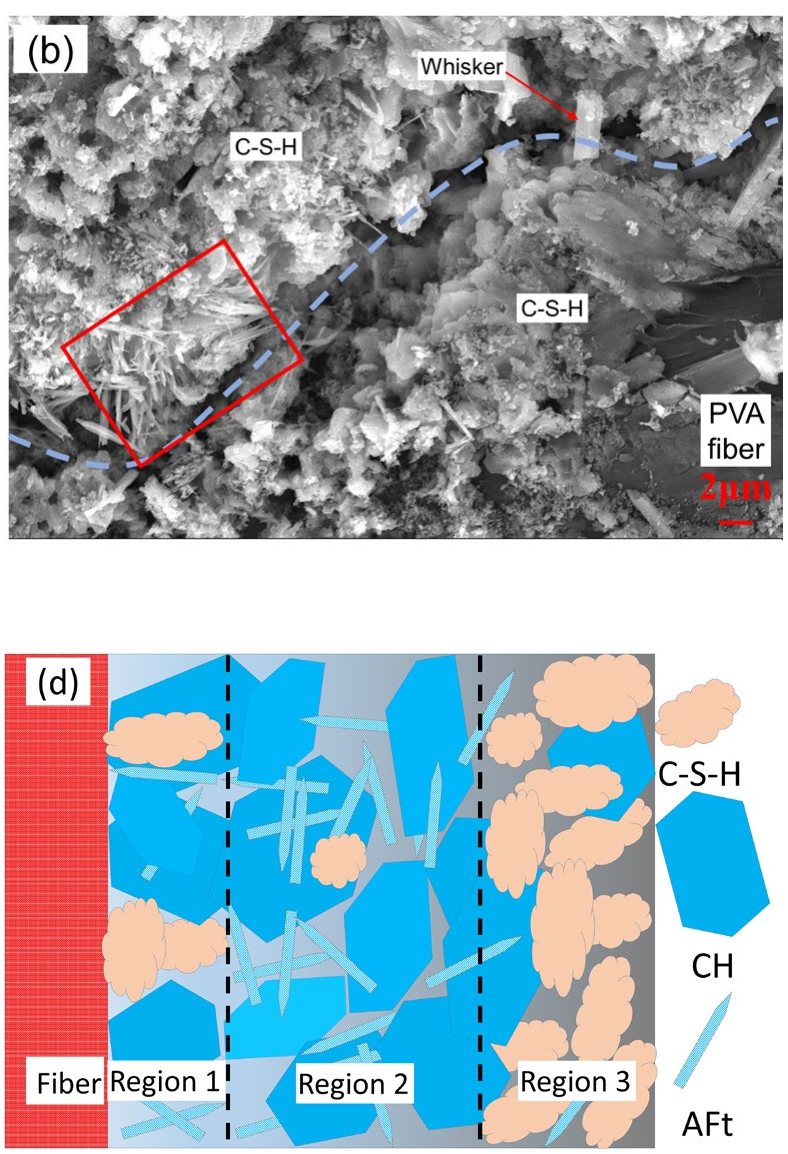

FIGURE 7. Micro-structure of the interface between the fibers and the matrix. 
and AFt gradually decreased. Region 3 eventually became consistent with the matrix, forming a compact structure dominated by C-S-H gel.

As shown in Figure 8, to further explore the ITZ formation mechanism of the steel and PVA fibers in cementitious materials, EDS was used to analyze the elemental composition in the ITZ, and the results are shown in Figure 9. The overall silicon content gradually increased from the fiber surface to the exterior, and the C-S-H gel gradually increased and became stable. However, due to the differences in the physical properties and sizes of the fibers, the ITZ sizes were different. Thus, the ITZ width for the steel fiber was about $45-50 \mu \mathrm{m}$, which was close to the results reported by Xu et al. (28). The ITZ width for the PVA fiber was about $20-25 \mu \mathrm{m}$, which was also close to the width of ITZ of polypropylene fibers (28).

The formation mechanism of the weak ITZ for steel and PVA fibers in cementitious materials is shown in Figure 10, namely showing the "wall effect" (28). As shown in Figure 9, in region 2, there was an obvious "fovea" in the silicon and calcium content curve, and the molar percentage decreased. Thus, the region with the least amount of C-S-H gel content did not appear in region 1 , close to the fiber, but in region 2 slightly away from the fiber. As shown in Figure 9(a), in region 1, $\mathrm{Fe}^{2+}$ content was significantly higher than in regions 2 and 3. This result was mainly due to the dissolution of the steel fiber, forming more hydration products, and reducing

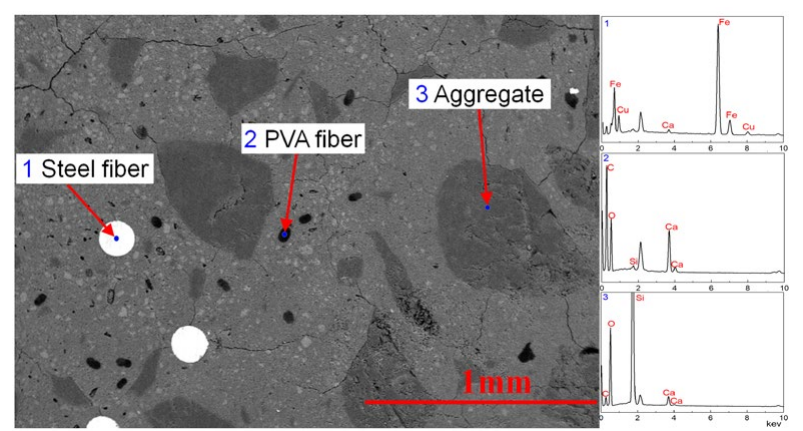

FIGURE 8. Backscattered electron (BSE) image of the MSFRCM.

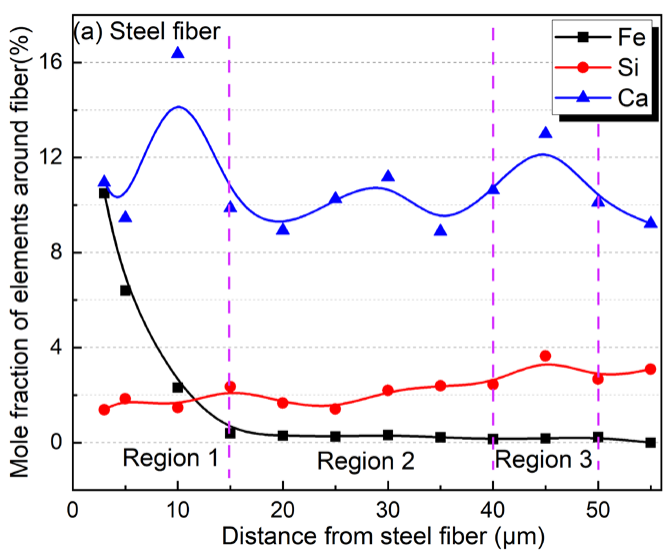

FigURE 9. Elemental mole fractions of the fiber and cement matrix interfaces.

the adverse effects of the water film layer in region 1 (28). As shown in Figure 9(b), the concentration of calcium ions on the surface of the PVA fiber was higher, because the PVA fiber contained abundant hydroxyl radicals with a strong adsorption capacity for $\mathrm{Ca}^{2+}$. Hence, the hydration products easily enriched the surface of the PVA fiber, forming a relatively dense region 1 .

The presence of CW in the MSFRCM optimized and improved the weak ITZ on the steel and PVA fiber surfaces, as shown in Figure 11. The main mechanism consisted of physical effects, such as bridging and filling effects, as shown in Figure 7(b) and (c). The weak ITZ of the steel and PVA fibers was mainly composed of $\mathrm{Ca}(\mathrm{OH})_{2}$ and $\mathrm{Aft}$, and $\mathrm{CW}$ influenced $\mathrm{Ca}(\mathrm{OH})_{2}$ and AFt via chemical effects. As described in (16), $\mathrm{CWs}$ can reduce the orientation index of $\mathrm{Ca}(\mathrm{OH})_{2}$ in cementitious materials, and when in the presence of $\mathrm{CW}, \mathrm{Ca}(\mathrm{OH})_{2}$ amount is reduced when space is limited and constrained. Thus, the $\mathrm{Ca}(\mathrm{OH})$, crystal was refined, and the ITZ density improved. This was one of the reasons why the mechanical properties of the fiber-reinforced cementitious materials containing $\mathrm{CW}$ improved, as discussed in Section 3.

\subsection{Mechanism analysis of multi-scale fibers in the MSFRCM}

When cementitious materials begin to crack and fail, the steel fibers, PVA fibers, and CW in MSFRCMs can bridge the cracks at the macro, mesoscopic, and microscopic levels, respectively. This inhibited crack propagation, consumed energy, and improved the strength and toughness of the cementitious material. The multi-scale crack resistance principle is shown in Figure 12.

Figure 13 shows the action of the multi-scale fibers at various loading stages during the uniaxial tensile loading process. The micron-sized $\mathrm{CW}$ inhibited the initial extension of micron grade defects under loading and improved the initial crack strength of the cementitious material, namely in stage 1 . With the

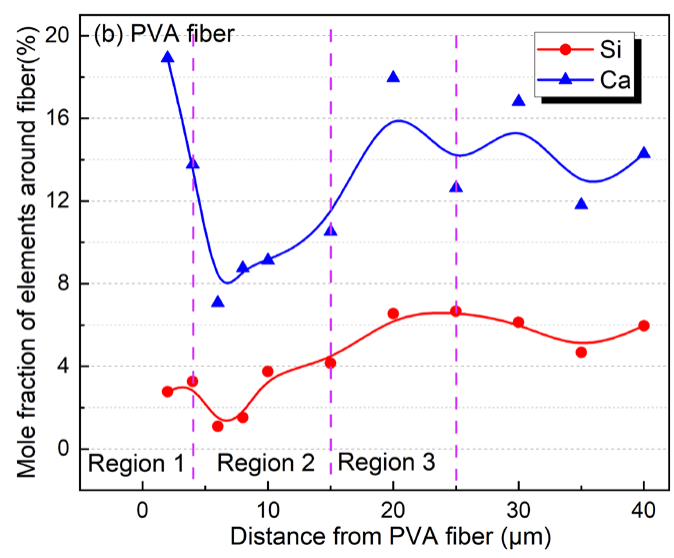

Materiales de Construcción 72 (345), January-March 2022, e271, ISSN-L: 0465-2746. https://doi.org/10.3989/mc.2022.05521 


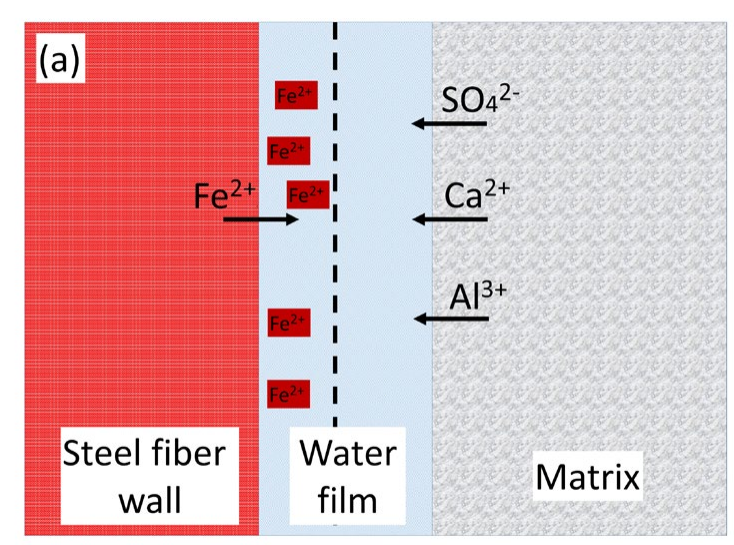

(a) Steel fiber surface

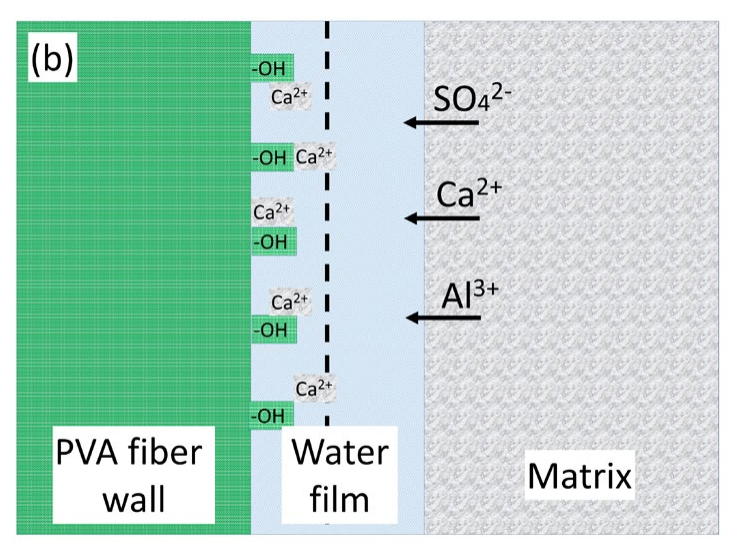

(b) PVA fiber surface

FigURE 10. Mechanisms of the fiber and cement matrix interfaces.

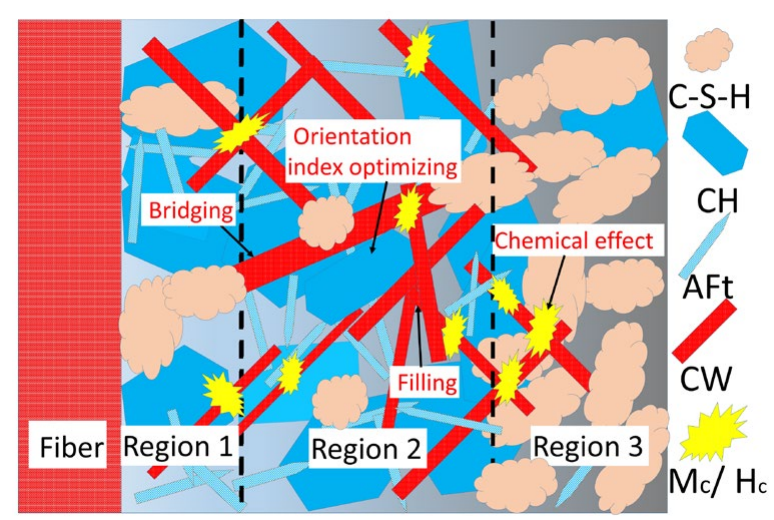

FiguRe 11. Fiber ITZ enhanced by CWs.

continuous increase in tensile stress, the $\mathrm{CW}$ material pulled out from the matrix or broke, internal forces were redistributed through the matrix, and the initial defects combined, forming micro-cracks. Additionally, the fine aggregate and PVA fibers restricted the development of cracks by bridging action in stage 2 .

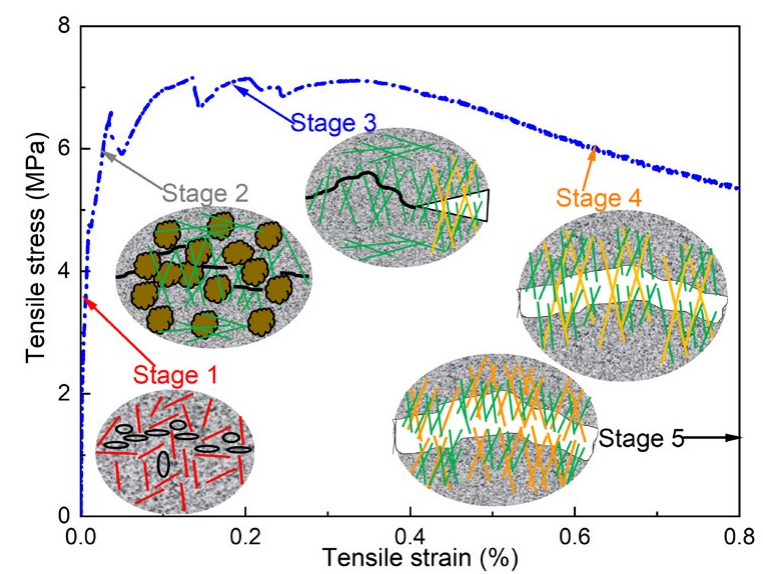

FIGURE 13. Effects of multi-scale fibers at different stages during the uniaxial tensile test.

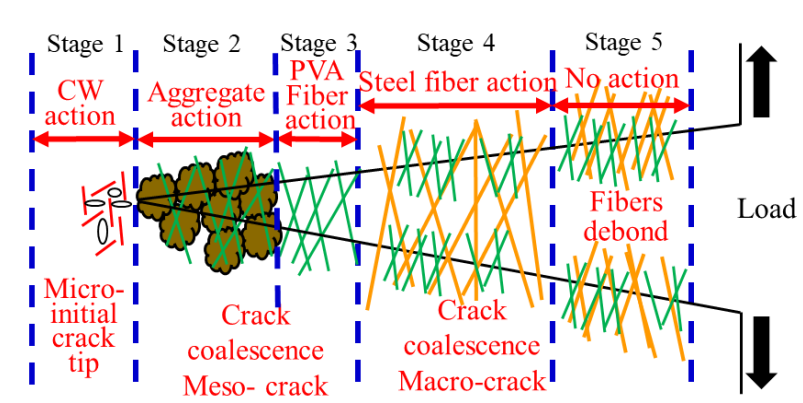

FIGURE 12. Crack restriction effect by the multi-scale fibers.

Then the micro-cracks gradually coalesced, the fine aggregate debonded, and the PVA fibers started to pull out and break under load. Macroscopically, this occurred in the form of cracks that were visible to the naked eye. Due to the strong deformation capability of the PVA fibers, this process consumed energy and diffused stress during the pull-out process, and a certain degree of strain hardening appeared on the curve. This macroscopically manifested as multi-cracks, in stage 3. After reaching peak load,

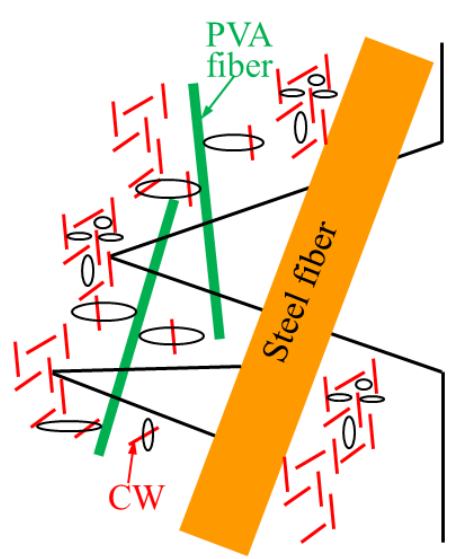

FIGURE 14. Interactions between the multi-scale fibers. 
the cracks continued to expand, and the deformation increased significantly, with a large number of PVA fibers pulling out from the matrix. However, the steel fibers still bridged the crack, effectively maintaining the load-holding capacity of the MSFRCM during the post-peak large deformation stage. Consequently, the load attenuation rate during the post-peak stage of the stress-strain curve significantly slowed down in stage 4. Under the continuous action of tensile stress, cracks continued to develop, and deformation further increased. Finally, a large number of steel fibers were pulled out from the matrix, and the MSFRCM was destroyed in stage 5 .

The effects of CW and the PVA and steel fibers not only were independent at different scales but also exhibited significant mutual effects, as shown in Figure 14. However, the small-scale CW and PVA fibers did improve the properties of the matrix by controlling the small-scale defects and micro-cracks. This enhanced the holding force of the matrix on the large-scale steel fibers, strengthening the reinforcing effect of the steel fibers. Additionally, when the large steel fibers were pulled out by force, the internal forces were redistributed in the matrix, and new tiny cracks were generated along the periphery of the steel fiber. These cracks were restricted by the PVA fibers and the CW; thus, the PVA fibers and CW continued to have an effect. Therefore, the interactions between the multi-scale fibers in the MSFRCM were the result of interactions and dynamic and chain reactions, which can be called the "fiber chain effect." This was the cause of the positive hybrid effect of the fibers described in Section 3.

\section{CONCLUSIONS}

The following conclusions were drawn from the results of this study.

(1) The hybrid combination of steel fiber, PVA fiber, and CW presented noteworthy improvements in the uniaxial tensile behavior of cementitious materials. Specifically, CW improved the uniaxial tensile stiffness, strength, peak strain, and toughness of the steel-PVA hybrid fiber-reinforced cementitious materials. The $\mathrm{CW}$ not only played a role during the small deformation stage but also improved the load holding capacity and toughness of the hybrid fiber-reinforced cementitious materials during the large deformation stage. A fiber combination of $1.5 \%$ steel fiber $+0.5 \%$ PVA fiber $+1 \% \mathrm{CaCO}_{3} \mathrm{CW}$ performed the best.

(2) Based on test data, a mathematical formula analyzing the relationship between the uniaxial tensile properties and the fiber characteristic parameter $\mathrm{RI}_{V}$ of the MSFRCM was proposed. $\mathrm{RI}_{V}$ reflected the effect of fiber tensile strength and mechanical anchoring properties on the tensile properties of the
MSFRCM. This formula was in the form of a quadratic function, reflecting the toughening effect of the hybrid fiber system on the MSFRCM. By analyzing data from the experiment and the literature, we found that the mathematical model applied well to the hybrid fiber-reinforced cementitious materials.

(3) The microstructure observations showed that the steel and PVA fibers formed weak ITZ areas due to the "wall effect." The fiber/matrix ITZ formation mechanisms were different for the steel and PVA fibers. The Fe ions that dissolved from the steel fibers may have increased the density of the cement stone structure on the fiber surface. Furthermore, the abundance of hydroxides from the PVA fiber also resulted in a relatively dense cement structure on the fiber surface. The CW effectively optimized the ITZ structure for the steel and PVA fibers by physical and chemical effects, such as filling, bridging, improving $\mathrm{Ca}(\mathrm{OH})_{2}$ orientation, and chemical effects.

(4) The steel fibers, PVA fibers, and the $\mathrm{CW}$ in the MSFRCM bridged cracks at the macro, mesoscopic, and microscopic levels, respectively. This inhibited crack propagation, consumed energy, and improved the tensile strength and toughness of the cementitious materials. Consequently, we observed a fiber chain effect that improved the positive hybrid effect between the multi-scale fibers.

\section{ACKNOWLEDGMENTS}

The authors acknowledge the financial support by Chinese Universities Scientific Fund (2452020054), Natural Science Basic Research Plan in Shaanxi Province of China (2021JQ-174), and Opening Project of State Key Laboratory of Green Building Materials (2020GBM10). We thank LetPub (www. letpub.com) for its linguistic assistance during the preparation of this manuscript.

\section{AUTHOR CONTRIBUTIONS:}

Conceptualization: L. Li, M. Cao. Data curation: L. Li, D. Shi, K. Shi.. Formal analysis: L. Li. Investigation: Z. Li. Methodology: M. Cao, Z. Li. Supervision: M. Cao. Roles/Writing, original draft: L. Li. Writing, review \& editing: L. Li, W. Zhang.

\section{REFERENCES}

1. Xu, L.; Huang, L.; Chi, Y.; Mei, G. (2016) Tensile behavior of steel-polypropylene hybrid fiber-reinforced concrete. Aci Mater. J. 113 [2]: 219-229.

2. Yang, Y.; Zhou, Q.; Deng, Y.; Lin, J. (2020) Reinforcement effects of multi-scale hybrid fiber on flexural and fracture behaviors of ultra-low-weight foamed cement-based composites. Cem. Concr. Compos. 108,103509. https://doi. org/10.1016/j.cemconcomp.2019.103509.

3. Zhang, Y.; Ju, J.W.; Zhu, H.; Yan, Z. (2020) A novel multiscale model for predicting the thermal damage of hybrid 
fiber-reinforced concrete. Int. J. Damage Mech. 29 [1], 1944. https://doi.org/10.1177/1056789519831554.

4. Bao, J.; Li, S.; Zhang, P.; Ding, X.; Xue, S.; Cui, Y. (2020) Influence of the incorporation of recycled coarse aggregate on water absorption and chloride penetration into concrete. Constr. Build. Mater. 239, 117845. https://doi.org/10.1016/j. conbuildmat.2019.117845.

5. Bao, J.; Xue, S.; Zhang, P.; Dai, Z.; Cui, Y. (2020) Coupled effects of sustained compressive loading and freeze-thaw cycles on water penetration into concrete. Struct. Concrete. 22 [S1], E944-E954. https://doi.org/10.1002/suco.201900200.

6. Li, L.; Cao, M.; Xie, C.; Yin, H. (2019) Effects of $\mathrm{CaCO}_{3}$ whisker, hybrid fiber content and size on uniaxial compressive behavior of cementitious composites. Struct. Concrete. 20 [1], 506-518. https://doi.org/10.1002/suco.201800185.

7. Cao, M.; Li, L.; Shen, S. (2019) Influence of reinforcing index on rheology of fiber-reinforced mortar. Aci Mater. J. 116 [6], 95-105. https://doi.org/10.14359/51716816.

8. Cao, M.; Li, L.; Khan, M. (2018) Effect of hybrid fibers, calcium carbonate whisker and coarse sand on mechanical properties of cement-based composites. Mater. Construcc. 68 [330], e156. https://doi.org/10.3989/mc.2018.01717.

9. Cao, M.; Li, L. (2018) New models for predicting workability and toughness of hybrid fiber reinforced cement-based composites. Constr. Build. Mater. 176, 618-628. https://doi. org/10.1016/j.conbuildmat.2018.05.075.

10. Li, L.; Cao, M. (2018) Influence of calcium carbonate whisker and polyvinyl alcohol- steel hybrid fiber on ultrasonic velocity and resonant frequency of cementitious composites. Constr. Build. Mater. 188, 737-746. https://doi.org/10.1016/j. conbuildmat.2018.08.154.

11. Yang, Y.; Deng, Y.; Li, X. (2019) Uniaxial compression mechanical properties and fracture characteristics of brucite fiber reinforced cement-based composites. Compos. Struct. 212, 148-158. https://doi.org/10.1016/j. compstruct.2019.01.030.

12. Pan, J.; Cai, J.; Ma, H.; Leung, C.K.Y. (2018) Development of multiscale fiber-reinforced engineered cementitious composites with pva fiber and $\mathrm{CaCO}_{3}$ whisker. $A S C E J$. Mater. Civ. Eng. 30 [6], 40181066. https://doi.org/10.1061/ (ASCE)MT.1943-5533.0002305

13. Li, L.; Li, Z.; Cao, M.; Tang, Y.; Zhang, Z. (2021) Nanoindentation and porosity fractal dimension of calcium carbonate whisker reinforced cement paste after elevated temperatures (up to $900^{\circ} \mathrm{C}$ ). Fractals. 29 [2], 2140001. https://doi.org/10.1142/S0218348X21400016.

14. Wang, B.; Han, Y.; Liu, S. (2013) Effect of highly dispersed carbon nanotubes on the flexural toughness of cement-based composites. Constr. Build. Mater. 46, 8-12. https://doi. org/10.1016/j.conbuildmat.2013.04.014.

15. Metaxa, Z.S.; Konsta-Gdoutos, M.S.; Shah, S.P. (2013) Carbon nanofiber cementitious composites. Effect of debulking procedure on dispersion and reinforcing efficiency. Cem. Concr. Compos. 36, 25-32. https://doi.org/10.1016/j. cemconcomp.2012.10.009.
16. Li, L.; Cao, M.; Yin, H. (2019) Comparative roles between aragonite and calcite calcium carbonate whiskers in the hydration and strength of cement paste. Cem. Concr. Compos. 104, 103350. https://doi.org/10.1016/j. cemconcomp.2019.103350.

17. Li, L.; Xie, C.; Cao, M.; Zhou, X.; Li, Z. (2021) Synergistic effect between $\mathrm{CaCO}_{3}$ whisker and steel-pva fibre cocktail in cement-based material at elevated temperature. ASCE J. Mater. Civ. Eng. https://doi.org/10.1061/(ASCE)MT.19435533.0004103

18. Khan, M.; Cao, M.; Ali, M. (2018) Effect of basalt fibers on mechanical properties of calcium carbonate whisker-steel fiber reinforced concrete. Constr. Build. Mater. 192, 742-753. https://doi.org/10.1016/j.conbuildmat.2018.10.159.

19. Wille, K.; El-Tawil, S.; Naaman, A.E. (2014) Properties of strain hardening ultra high performance fiber reinforced concrete (UHP-FRC) under direct tensile loading. Cem. Concr. Compos. 48, 53-66. https://doi.org/10.1016/j.cemconcomp.2013.12.015.

20. Park, S.H.; Kim, D.J.; Ryu, G.S.; Koh, K.T. (2012) Tensile behavior of ultra high performance hybrid fiber reinforced concrete. Cem. Concr. Compos. 34 [2], 172-184. https://doi. org/10.1016/j.cemconcomp.2011.09.009.

21. Mansour, M.Y.; Hsu, T.T.C.; Mo, Y.L. (2009) Constitutive relations of cracked reinforced concrete with steel fibers. ACI Special Publication. 265, 101-122. Retrieved from https://www.concrete.org/publications/ internationalconcreteabstractsportal $? \mathrm{~m}=$ details\& $\mathrm{i}=51663292$.

22. Lu, C.; Leung, C.K.Y.; Li, V.C. (2017) Numerical model on the stress field and multiple cracking behavior of Engineered Cementitious Composites (ECC). Constr. Build. Mater. 133, 118-127. https://doi.org/10.1016/j.conbuildmat.2016.12.033.

23. Cao, M.; Li, L.; Xu, L. (2017) Relations between rheological and mechanical properties of fiber reinforced mortar. Comput. Concr. 20 [4], 449-459. https://doi.org/10.12989/ cac.2017.20.4.449.

24. Li, V.C.; Kong, H.J.; Chan, Y.W. (1998) Development of selfcompacting engineered cementitious composites. J. Cem. Concr. Compos. 25 [2], 301-309.

25. Li, Q.; Gao, X.; Xu, S. (2016) Multiple effects of nano$\mathrm{SiO}_{2}$ and hybrid fibers on properties of high toughness fiber reinforced cementitious composites with high-volume fly ash. Cem. Concr. Compos. 72, 201-212. https://doi.org/10.1016/j. cemconcomp.2016.05.011.

26. Cao, M.; Li, L.; Yin, H.; Ming, X. (2019) Microstructure and strength of calcium carbonate $\left(\mathrm{CaCO}_{3}\right)$ whisker reinforced cement paste after exposed to high temperatures. Fire Technol. 55 [6], 1983-2003. https://doi.org/10.1007/s10694-019-00839-3.

27. Yang, Y.; Fu, S.; Li, X. (2017) Mechanical attributes of uniaxial compression for calcium carbonate whisker reinforced oil well cement pastes. Adv. Mater. Sci. Eng. 2017, 2939057. https://doi.org/10.1155/2017/2939057.

28. Xu, L.; Deng, F.; Chi, Y. (2017) Nano-mechanical behavior of the interfacial transition zone between steel-polypropylene fiber and cement paste. Constr. Build. Mater. 145, 619-638. https://doi.org/10.1016/j.conbuildmat.2017.04.035. 